\title{
Pulmonary exposure to carbonaceous nanomaterials and sperm quality
}

\author{
Astrid Skovmand ${ }^{1,2}$ (D) Anna Jacobsen Lauvås², Preben Christensen ${ }^{3}$, Ulla Vogel ${ }^{1,4}$, Karin Sørig Hougaard ${ }^{1,5}$ \\ and Sandra Goericke-Pesch ${ }^{2 *}$
}

\begin{abstract}
Background: Semen quality parameters are potentially affected by nanomaterials in several ways: Inhaled nanosized particles are potent inducers of pulmonary inflammation, leading to the release of inflammatory mediators. Small amounts of particles may translocate from the lungs into the lung capillaries, enter the systemic circulation and ultimately reach the testes. Both the inflammatory response and the particles may induce oxidative stress which can directly affect spermatogenesis. Furthermore, spermatogenesis may be indirectly affected by changes in the hormonal milieu as systemic inflammation is a potential modulator of endocrine function. The aim of this study was to investigate the effects of pulmonary exposure to carbonaceous nanomaterials on sperm quality parameters in an experimental mouse model.
\end{abstract}

Methods: Effects on sperm quality after pulmonary inflammation induced by carbonaceous nanomaterials were investigated by intratracheally instilling sexually mature male NMRI mice with four different carbonaceous nanomaterials dispersed in nanopure water: graphene oxide (18 $\mu \mathrm{g} /$ mouse/i.t.), Flammruss 101, Printex 90 and SRM1650b (0.1 mg/ mouse/i.t. each) weekly for seven consecutive weeks. Pulmonary inflammation was determined by differential cell count in bronchoalveolar lavage fluid. Epididymal sperm concentration and motility were measured by computer-assisted sperm analysis. Epididymal sperm viability and morphological abnormalities were assessed manually using Hoechst 33,342/PI flourescent and Spermac staining, respectively. Epididymal sperm were assessed with regard to sperm DNA integrity (damage). Daily sperm production was measured in the testis, and testosterone levels were measured in blood plasma by ELISA.

Results: Neutrophil numbers in the bronchoalveolar fluid showed sustained inflammatory response in the nanoparticleexposed groups one week after the last instillation. No significant changes in epididymal sperm parameters, daily sperm production or plasma testosterone levels were found.

Conclusion: Despite the sustained pulmonary inflammatory response, an eight week exposure to graphene oxide, Flammruss 101, Printex 90 and the diesel particle SRM1650b in the present study did not appear to affect semen parameters, daily sperm production or testosterone concentration in male NMRI mice.

Keywords: Nanomaterials, Particles, Toxicity, Semen parameters, Pulmonary exposure, Computer-assisted sperm analysis, Inflammation

\footnotetext{
* Correspondence: Sandra.Goericke-Pesch@tiho-hannover.de

${ }^{2}$ Section for Veterinary Reproduction and Obstetrics, Department of

Veterinary Clinical Sciences, University of Copenhagen, Dyrlægvej 68,

DK-1870 Frederiksberg C, Denmark

Full list of author information is available at the end of the article
}

(c) The Author(s). 2018 Open Access This article is distributed under the terms of the Creative Commons Attribution 4.0 International License (http://creativecommons.org/licenses/by/4.0/), which permits unrestricted use, distribution, and reproduction in any medium, provided you give appropriate credit to the original author(s) and the source, provide a link to the Creative Commons license, and indicate if changes were made. The Creative Commons Public Domain Dedication waiver (http://creativecommons.org/publicdomain/zero/1.0/) applies to the data made available in this article, unless otherwise stated. 


\section{Background}

The use and development of nanotechnology have been rapidly increasing. The ever expanding application of nanomaterials (NMs) includes areas such as cosmetics, electronics and food science, and as a result, men in the reproductive age are potentially exposed to nanomaterials both as workers in the various industries and as consumers. Likewise, the general public can also be exposed due to the release of nanoparticles (NPs) into the environment from natural and anthropogenic sources. The male germ line is highly sensitive to toxic insults and a number of environmental toxicants, such as ionizing radiation, organic solvents, and heavy metals, markedly decrease semen quality [1]. The apparent worldwide decline in semen quality, a controversial and often debated statement, has been reported by several researchers [2-4]. Linear regression analysis of 138 published reports from Europe, North and South America, and Asia between 1980 and 2015 showed a 57\% decrease in mean sperm concentration in men [4]. Danish researchers, for example, have reported a decreasing trend and although recent monitoring programs now document a slight increase in semen quality in young Danish men, only one out of four has optimal semen quality [3]. Air pollution and its particulate constituents have been associated with several adverse health effects, mainly pulmonary and cardiovascular diseases [5]. Epidemiological studies of adult men have, however, also found that elevated levels of air pollution are associated with decreased sperm motility, increased percentages of morphologically abnormal sperm, and elevated levels of DNA damage in sperm $[6,7]$. Consequently, the question of whether NMs can affect male fertility by decreasing semen quality parameters merits further investigation.

The mechanisms how inhaled NMs may affect semen quality are yet to be elucidated. It has been hypothesised that NMs may affect semen quality in several ways: when inhaled, particles are potent inducers of pulmonary inflammation, which may result in the release of inflammatory mediators into the blood stream. Small amounts of particles may also translocate from the lungs into the lung capillaries and enter the blood stream [8]. The systemic inflammation may weaken the integrity of the blood-testis-barrier and increase its permeability, ultimately allowing NMs that have deposited in the testis to enter the lumen of the seminiferous tubules [9]. An inflammatory response in the testis may be induced due to infection, trauma and/or environmental toxins. Accordingly, it may be possible that NMs in the testis may elicit a testicular inflammatory response and thus possibly activate resident macrophages or result in an influx of neutrophils and other leukocytes [10]. Particles and leukocytes may create a Reactive
Oxygen Species (ROS)/antioxidant imbalance, as both the particles and the leukocytes are strong inducers of ROS [11]. High levels of oxidative stress have been hypothesised to be a major cause for male infertility, because spermatozoa are highly sensitive to oxidative damage [12].

Exposure to NMs may also indirectly affect spermatogenesis by affecting the hormonal milieu via effects on the hypathalamic-pituitay-gonadal axis, as this axis is sensitive to inflammation. In female mice, it has been recently shown that airway exposure to multi-walled carbon nanotubes can interfere with the estrous cycle by either direct action of the particles or indirectly by the influence of inflammatory and acute phase responses [13]. NP-rich diesel exhaust inhalation exposure (5 h/ day, 5 days/week) of adult male Fisher 344 rats increased plasma testosterone levels, possibly due to the induction of testosterone biosynthesis through elevation of StAR and P450scc in the testis via growth hormone signaling. Interestingly, the NP-rich diesel exhaust did not show dose-dependent effects, high levels of testosterone were found at the low $\left(2.27 \times 10^{5} / \mathrm{cm}^{3}\right)$ and medium $(5.11 \times$ $10^{5} / \mathrm{cm}^{3}$ ) exposure levels whereas testosterone concentrations remained unchanged at the high $\left(1.36 \times 10^{6}\right.$ $/ \mathrm{cm}^{3}$ ) exposure level [14]. In ICR mice, inhalation exposure (12 h/day for 6 months) to diesel exhaust at $0.3,1$ and $3 \mathrm{mg} \mathrm{DEP} / \mathrm{m}^{3}$, has been shown to cause degenerative and necrotic changes in the testis, desquamation of the seminiferous tubules and loss of spermatozoa, degenerative changes in Leydig cells such as the appearance of myelin, lipid droplets and secondary lysosomes, and a reduction in daily sperm production (DSP) [15]. In the same strain, 10 weekly exposures to $0.1 \mathrm{mg} /$ mouse by intratracheal instillation (i.t.) of three different sizes of carbon black (CB) NPs (14, 56, and $95 \mathrm{~nm})$ were shown to significantly decrease DSP, increase testosterone levels and cause vacuolation of the seminiferous tubules [16]. Following intratracheal instillation of $2 \mathrm{mg} / \mathrm{kg}$ (every 3 days for 45 days) of silica particles (57 nm), particles have been observed to cross the blood-testis-barrier in C57BL/6 mice using transmission electron microscopy. The silica NPs decreased sperm concentration and motility, and increased sperm abnormalities. Testicular malondialdehyde and 3-nitrotyrosine levels were increased, whereas SOD activity was impaired; suggesting that the damage may have arisen due to oxidative stress in the testis [17].

Based on these findings, we hypothesised that airway exposure to nanomaterials may interfere with normal spermatogenesis and decrease the quality of sperm, potentially altering male reproductive function. To further investigate and characterize these effects, sexually mature NMRI male mice were exposed to four carbonaceus NMs with different shape, size and surface 
chemistry and the effects on sperm quality parameters and testosterone concentrations were investigated.

\section{Methods \\ Experimental design}

One hundred and five male NMRI mice, purchased from Taconic Biosciences Inc. (Ejby, Denmark), were acclimatized for one week prior to the commencement of the experimental procedures, which began when the mice were eight weeks of age. The mice were randomly divided into 7 groups $(n=15)$ : graphene oxide, Flammruss 101, Printex 90, SRM1650b, vehicle (nanopure water) controls, unhandled controls and high fat diet (HFD) controls. The graphene oxide, Flammruss 101, Printex 90 and SRM1650b exposed animals were intratracheally instilled with $50 \mu \mathrm{l}$ of particle suspension followed by $200 \mu \mathrm{l}$ of air under general anesthesia with 3-4\% isoflurane mixed with sterile filtered air as described by Jackson et al. [18]. The mice were instilled once a week for seven consecutive weeks and the study was terminated six to eight days after the last exposure resulting in a total exposure time of 1.6 spermatogenic cycles, as one spermatogenic cycle corresponds to $\sim 35$ days in mice. All the mice in the $\mathrm{CB}$ and diesel exhaust particle groups received the same dose of $0.1 \mathrm{mg} /$ mouse per instillation, corresponding to a cumulative dose of $0.7 \mathrm{mg}$ during the study period. The current occupational exposure limit in Denmark is $3.5 \mathrm{mg} / \mathrm{m}^{3}$ for CB. However, mean concentrations of $14.90 \mathrm{mg} / \mathrm{m}^{3}$ of $\mathrm{CB}$ have been measured by personal air samplers in the workplace [19]. Based on the observed particle size distribution during aerosolisation of particles [20], at the current occupational exposure limit of $3.5 \mathrm{mg} / \mathrm{m}^{3}$, the estimated deposited dose is $16.6 \mu \mathrm{g}$ in mice, giving a weekly deposited dose of $83 \mu \mathrm{g}$. $[20,21]$. The graphene oxide was administered at a lower dose of $18 \mu \mathrm{g} / \mathrm{mouse}$ per instillation, with a cumulative dose of $126 \mu \mathrm{g}$, to ensure that the animal's welfare was not affected, based on previous findings [22]. The vehicle control group was treated as the particle exposed group and received instillations of $50 \mu \mathrm{l}$ of nanopure water without NMs. The unhandled and HFD control groups did not receive instillations or isoflurane at any time. All 105 animals were randomly euthanized by exsanguination under deep anaesthesia with a cocktail of ZRF (Zoletil $250 \mathrm{mg}$, Rompun $20 \mathrm{mg} / \mathrm{ml}$ and Fentanyl $50 \mathrm{mg} / \mathrm{ml}$ in sterile isotone saline) at a dose of $0.01 \mathrm{ml}$ per g body weight. Due to logistical reasons half of the mice in each group were euthanized six or eight days after the last instillation. Testicles and epididymides were collected and weighed separately. The right testicle was snap frozen in liquid nitrogen and the left testicle was stored in Bouin's fixation solution. The head and tail of the epididymides were separated; the right and left head and the right tail were snap frozen individually. The left tail was used for sperm retrieval (see below).

The mice were housed individually in clear 1290D euro standard type 3 cages with aspen sawdust bedding (Tapvei, Estonia) and enrichment, nesting material (Enviro Dri, Lillico, Biotechnology, UK), mouse house (80ACRE011, Techniplast, Italy) and small aspen blocks (Tapvei, Estonia). Housing conditions were kept constant, with a 12:12 h light and dark cycle at an average temperature of $22{ }^{\circ} \mathrm{C}$ and $55 \%$ humidity. Tap water and standard pellet diet Altromin no. 1324 (Brogaarden, Denmark) were provided ad libitum to all groups, except for the HFD control group which received a $60 \% \mathrm{kcal}$ fat diet ad libitum upon arrival and throughout the study (RD Western Diet D12492, Open Source Diets, Brogaarden, Denmark). All experimental procedures followed the handling guidelines established by the Danish government and permits from the Experimental Animal Inspectorate (no. 201515-0201-00465 and 2015-15-0201-00569). Prior to the study, specific experimental protocols were approved by the local Animal Ethics Council.

\section{Nanoparticles, preparation and characterization}

The physico-chemical properties of the studied particles have been assessed and reported previously [23-25] and are summarized in Table 1. The graphene oxide in aqueous suspension was manufactured and supplied by Graphenea (San Sebastian, Spain) and has been previously characterized in detail in Bengtson et al. [23]. In suspension it appears as flat plates consisting of mainly two to three stacked graphene layers with a lateral size of 2 $3 \mu \mathrm{m}$. The specific surface area has not been reported, but the corresponding reduced graphene oxide had a specific surface area of $338-411 \mathrm{~m}^{2} / \mathrm{g}$ [23]. The Flammruss 101 and Printex 90 carbon black NPs in powder form were gifts from Boesens Fabrikker ApS (Denmark) and Degussa (Germany), respectively, and have been previously characterized in detail by Saber et al. [24]. Flammruss 101 consists of spherical particles with a primary particle diameter of $95 \mathrm{~nm}$ and a specific surface area of $23.8 \mathrm{~m}^{2} / \mathrm{g}$ [24]. Printex 90 has a similar shape to that of the Flammruss 101, with a reported primary particle diameter of $14 \mathrm{~nm}$ and a specific surface area of 295-338 $\mathrm{m}^{2} / \mathrm{g}$ [24]. The diesel exhaust particle (SRM1650b) is a standard reference material and the certificate of analysis is available from the National Institute of Standards \& Technology (Gaithersburg, MD, USA, https://www.nist.gov/). It is an exhaust particle from a heavy duty diesel engine with a reported primary particle diameter of $18-30 \mathrm{~nm}$ and a specific surface area of $108 \mathrm{~m}^{2} / \mathrm{g}$ [25]. Unlike the other three particles, the SRM1650b has a high content of adhered heavy metals and polycyclic aromatic hydrocarbons (PAHs) i.e. 
Table 1 Summary of particle characteristics

\begin{tabular}{|c|c|c|c|c|c|}
\hline Particle & Primary particle size & Shape & Surface area & Z-average (in nanopure water) & Reference \\
\hline Graphene oxide & $\begin{array}{l}\text { Lateral size: } 2-3 \mu \mathrm{m} \\
\text { Thickness: } 2 \mathrm{~nm}\end{array}$ & $\begin{array}{l}\text { flat plates consisting of } \\
\text { mainly two to three stacked } \\
\text { graphene layers }\end{array}$ & $\begin{array}{l}338-411 \mathrm{~m}^{2} / \mathrm{g} \\
\text { (reduced graphene oxide) }\end{array}$ & $486.7 \mathrm{~nm}$ & {$[31]$} \\
\hline Flammruss 101 & $95 \mathrm{~nm}$ & spherical & $23.8 \mathrm{~m}^{2} / \mathrm{g}$ & $305.4 \mathrm{~nm}$ & [32] \\
\hline Printex 90 & $14 \mathrm{~nm}$ & spherical & $295-338 \mathrm{~m}^{2} / \mathrm{g}$ & $147.2 \mathrm{~nm}$ & [32] \\
\hline SRM1650b & $18-30 \mathrm{~nm}$ & spherical & $108 \mathrm{~m}^{2} / \mathrm{g}$ & & [33] \\
\hline
\end{tabular}

a 3000 fold higher content of PAHs compared to Printex 90 [25].

For instillation, the particles were dispersed in nanopure water at a concentration of $2 \mathrm{mg} / \mathrm{ml}$ and sonicated for 16 min on ice using a $400 \mathrm{~W}$ Branson Sonifier A-450D (Branson Ultrasonic Corp., Danbury, CT, USA) equipped with a disruptor horn (Model 101-147-037). The hydrodynamic particle size distribution in nanopure water was measured by dynamic light scattering using a Malvern Zetasizer Nano ZS equipped with a $633 \mathrm{~nm}$ He-Ne Laser (Malvern Inc., UK).

\section{Bronchoalveolar lavage}

Bronchoalveolar lavage fluid (BALF) differential cell counts were performed as previously described in Kyjovska et al. [26]. The BALF was collected for 12 of the 15 mice per particle exposed group as the lungs of 3 mice per group were collected for histology. The trachea of the mice ( $n=12$ per group) was exposed and cannulated with a 22 gauge $\mathrm{BD}$ Insyte catheter. The lungs were flushed twice with $0.8 \mathrm{ml}$ of $0.9 \%$ saline in a $1 \mathrm{ml}$ syringe. The BALF was centrifuged at $400 \mathrm{~g}$ at $4{ }^{\circ} \mathrm{C}$ for $10 \mathrm{~min}$. The cell pellet was re-suspended in $100 \mu \mathrm{l}$ of Ham's F-12 Nutrient Mix cell culture medium. Total cells were counted using a NucleoCounter (Chemometec, NucleoCounter NC-200). For the differential cell counts $50 \mu \mathrm{l}$ of the BALF cell suspension were pipetted onto glass slides and spun at $1000 \mathrm{rpm}$ for $4 \mathrm{~min}$ in a cytospin centrifuge. The slides were fixated and then stained with May-Grünwald EosinMethyleneblue and Giemsa Azur-Eosin-Methylene Blue solution. Differential cell counts were performed under a bright field microscope using oil immersion and a 1000x magnification.

\section{Collection of epididymal sperm and computer-assisted sperm analysis of concentration, motility and viability}

The left epididymal tail was placed in $500 \mu \mathrm{l}$ warm (37 C) TCM199 medium (Sigma-Aldrich, Denmark) and minced with scissors. The sperm cells were allowed to swim out for $10 \mathrm{~min}$ and were then filtered through a stainless steel mesh. Samples were kept at $37{ }^{\circ} \mathrm{C}$ on a heating stage during the whole procedure including microscopy analysis. Computer-assisted sperm analysis (CASA) was performed using a negative phase contrast microscope (Olympus BX60, Tokyo, Japan) equipped with a heating stage and a high-speed GigE camera (avA21000$100 \mathrm{gc}$ ) with a CCD sensor (aviator series, Basler, Germany) detecting 101 frames/s and the AndroVision software (Ref 12,500/0000, Software Version 1.0.0.9, Minitube, Tiefenbach, Germany). For analysis of concentration and motility, an aliquot of the diluted semen $(2.0 \mu \mathrm{l})$ was pipetted into an evaluation chamber (Leja ${ }^{\circ}$ Standard Count 4 Chamber Slide, $10 \mu \mathrm{m}$, Leja Products B. V., Nieuw Vennep, The Netherlands) and 10 randomly distributed fields were analysed at $200 \times$ magnification. The software calculated the sperm concentration per $\mathrm{mL}$ and analysed the sperm motility parameters. Motility results were presented as the total percentage of motile spermatozoa and the percentage of progressively motile spermatozoa. The following settings on the CASA system were used: sperm recognition area $10-100 \mu \mathrm{m}^{2}, 10$ fields per sample, $\mathrm{TM}=$ $\mathrm{PM}+\mathrm{LM}, \mathrm{PM}=\mathrm{CM}+$ slow motility + fast motility, LM: velocity curved line $(\mathrm{VCL})<80 \times 10^{4} \mu / \mathrm{s}$ and velocity straight line $(\mathrm{VSL})<20 \times 10^{4} \mu / \mathrm{s}$, Circular Motility: linearity $<0.6000$ and rotation $>0.8000$.

Additionally, another aliquot $(50 \mu \mathrm{l})$ of the diluted semen was added to $1.5 \mu \mathrm{l}$ of ready to use Hoechst 33,342/PI fluorescent stain (Minitube) and incubated at $37{ }^{\circ} \mathrm{C}$ for $15 \mathrm{~min}$. The viability was analyzed manually by counting 200 sperm per sample using a fluorescent microscope fitted with a U-MU filter cube and a mercury burner. The results were presented as percentage of viable spermatozoa. Blue sperm were considered as viable, whereas red were considered as non-viable (www.minitube.com).

\section{Sperm morphology}

Native semen smears were prepared, air-dried, fixated and stained with Spermac ${ }^{\oplus}$ according to the manufacturer's instructions (Minitube). 200 spermatozoa were identified and categorized as normal or as having a morphological deviation. Deviations were differentiated into sperm acrosome, head, neck, mid-piece or tail defects, cytoplasmic droplets or loose heads. In case of several morphological deviations in one sperm, only the one considered as the most severe was recorded. The exposure status of the samples on morphology was blinded to the scorer. The results were presented as percentage of 
abnormal spermatozoa in the respective location as well as total percentage of normal spermatozoa as defined by $100 \%$ - each \% of abnormalities in the respective locations.

\section{Sperm DNA integrity}

Neat epididymal semen samples were diluted 1:2 with TNE buffer (0.01 M Tris-Cl, $0.15 \mathrm{M} \mathrm{NaCl}, 1 \mathrm{mM}$ EDTA, $\mathrm{pH}$ 7.4) and frozen directly at $-196{ }^{\circ} \mathrm{C}$ in a dryshipper and transported to the laboratory. The fluorescent staining was performed according to the protocol for the sperm chromatin structure assay as described by Evenson and Jost 2000 [27]. Semen samples were thawed at $35{ }^{\circ} \mathrm{C}$ for $3 \mathrm{~min}$ and were then incubated on ice for 5 min [28]. An aliquot of the thawed sample was diluted to a concentration of $2 \times 10^{6}$ sperm $/ \mathrm{mL}$ with TNE buffer to a total volume of $200 \mu \mathrm{L}$. DNA denaturation was induced by addition of $400 \mu \mathrm{L}$ acid detergent solution (0.08 M HCl, $0.15 \mathrm{M} \mathrm{NaCl}, 0.1 \% v / \mathrm{v}$ Triton X-100, $\mathrm{pH}$ 1.2). After $30 \mathrm{~s}, 1.20 \mathrm{~mL}$ of acridine orange staining solution (Citric acid $0.037 \mathrm{M}, \mathrm{Na}_{2} \mathrm{HPO}_{4} 0.126 \mathrm{M}, \mathrm{NaCl}$ $0.15 \mathrm{M}, \mathrm{Na}_{2}$ EDTA $1 \mathrm{mM}, \mathrm{pH}$ 6.0) were added. The sample was immediately placed in the flow cytometer and run through the system to allow for equilibration prior to acquisition of data. The samples were blinded and analyzed using a FACSCalibur (BD Biosciences) flow cytometer with an air-cooled argon orthogonal laser operating at $488 \mathrm{~nm}$ with $15 \mathrm{~mW}$ of power. After transiting a $560 \mathrm{~nm}$ short-pass dichroic mirror, the green fluorescence (FL1) was collected through a 515 to $545 \mathrm{~nm}$ band-pass filter and the red fluorescence (FL3) through a $650 \mathrm{~nm}$ long-pass filter. The sheath/sample was set to "high" with an estimated flow rate of $60 \mu \mathrm{l} /$ $\mathrm{min}$. This flow rate resulted in analysis of approximately 200 events per second. Acquisition of 5000 events was started exactly $3 \mathrm{~min}$ after initiation of the acid detergent treatment at a point in time when the sample had been running through the flow system for approximately $2.5 \mathrm{~min}$ to achieve equilibration. To ensure good quality control, each analysis was run in duplicate and results were only accepted, if the standard deviation (SD) between duplicates was below $2.5 \%$. If variation exceeded $2.5 \%$, two new aliquots were analyzed. If the event rate was above the expected 200 events per second, a new dilution and staining cycle was performed to ensure an event rate below 200 and thus an optimal ratio between acridine orange molecules and DNA. The results of the analyses were reported as DFI\% which describes the proportion of sperm with a detectable level of DNA damage after acid denaturation.

\section{Daily sperm production}

The adipose tissue from the frozen testes was trimmed and the tunica albuginea was peeled off with forceps after making a shallow longitudinal incision. The testes were weighed, placed into $4 \mathrm{ml}$ of $0.05 \%$ TRITON-X100 and homogenized for $3 \mathrm{~min}$ using the IKAULTRA TURRAX T25 disperser S25 N-10G. Homogenates were kept on ice for $30 \mathrm{~min} .200 \mu \mathrm{l}$ of the homogenate were mixed with $200 \mu \mathrm{l}$ of $0.04 \%$ Trypan blue and left for $5 \mathrm{~min}$ at room temperature. Sperm heads were counted using a Bürker counting chamber. DSP was calculated using the following formulas:

$\mathrm{N}=$ sperm number per $\mu \mathrm{l} \mathrm{x}$ volume of lysis (buffer)

DSP $=\mathrm{N} / 4.84$

where $\mathrm{N}$ is the total number of spermatids per sample. The DSP is then calculated by dividing the total number of spermatids per sample by 4.84 , which is the number of days for a spermatid to develop through stages 14 to 16 , i.e., the stages where spermatids are resistant to homogenization. The samples were blinded and counts were done in duplicates. If the two counts deviated by more than $20 \%$, the procedure was repeated for the sample.

\section{Testosterone measurement}

Blood was collected from the heart, stabilized using $\mathrm{K}_{2}$ EDTA and then centrifuged at $2500 \mathrm{~g}$ for $10 \mathrm{~min}$. The EDTA-plasma was pipetted into separate snapstrip PCRvials and stored at $-80{ }^{\circ} \mathrm{C}$ until analysis. The plasma samples were blinded and the testosterone concentrations were determined in duplicates and 1:2 dilutions with phosphate-buffered saline (PBS), using competitive ELISA (RTC001R, Biovendor, Brno, Czech Republic). Samples were analysed following the manufacturer's protocol, with a standard curve in the range of 0.1$25 \mathrm{ng} / \mathrm{mL}$. All samples that fell outside the standard curve were diluted 1:4 in PBS and re-analyzed. (Interassay) coefficient of variance was $4.8-7.8 \%$.

\section{Statistical analysis}

An ANOVA was used to test for the overall significance of the BALF counts and was followed by a Dunnett's test where particle exposed and unhandled control groups were compared to the vehicle control $\left(\mathrm{SAS}^{\circ}\right.$ software, version 9.4 of the SAS system for windows 7 (Cary, NC, USA)). All other data were analyzed by ANOVA, followed by post-hoc Fischer least statistical difference test when appropriate (Origin Pro, version 2016 (64-bit), OriginLab Corp (Northampton, MA, USA)). Results obtained from mice exposed to NMs were compared to those from vehicle-exposed mice, whereas results from HFD mice were compared to those of unhandled controls. The level of significance was set at 0.05 . The $a$ priori statistical power analysis had been calculated using the $33 \% \pm$ SD difference in DSP between the Printex 90 and vehicle control exposed mice reported by Yoshida et al. 2008 (16) (G*Power software version 3.1.9.2, Düsseldorf, Germany). 


\section{Results}

\section{Nanoparticle characterization}

The graphene oxide, Flammruss 101 and Printex 90 dispersed in nanopure water at a concentration of $2 \mathrm{mg} / \mathrm{ml}$ had a Z-average of $486.7 \mathrm{~nm}, 305.4 \mathrm{~nm}$ and $147.2 \mathrm{~nm}$, respectively. Due to a lack of material the DLS was not performed on the SRM1650b, however, the SRM1650b dispersed in nanopure water at a concentration of $3.24 \mathrm{mg} / \mathrm{ml}$ was previously measured to have a Zaverage of $167.8 \mathrm{~nm}$ (25). The particles characteristics are summarized in Table 1.

\section{Body, testicular and epididymal weights}

There was no difference in body weight and absolute and relative organ weight between the groups, except for the HFD controls which had a statistically significantly higher body weight compared to all other groups (Table 2). However, only five out of the 15 mice in the HFD group gained enough weight to be considered obese, which means mice weighing more than $51.27 \mathrm{~g}$, based on the mean weight of the unhandled +2 SD.

\section{Pulmonary inflammation}

BALF neutrophil numbers were significantly elevated in the lungs from mice exposed to graphene oxide (51-fold increase), Flammruss 101 (61-fold increase), Printex 90 (329-fold increase) and SRM1650b (78-fold increase) compared to vehicle controls $(p<0.001)$ (Table 3$)$. The unhandled and the HFD were not statistically different from the vehicle control group, confirming that the instillation procedure and the vehicle did not induce pulmonary inflammation. Interestingly, Printex 90 induced a stronger inflammatory response one week after the last instillation compared to the other three NMs. Neutrophil influx was plotted against deposited surface area since surface area may be a more biological relevant dose metric for spherical NMs than mass (see Additional file 1). Neutrophil cell numbers correlated with deposited surface area $\left(R^{2}=0.64\right)$.
Epididymal sperm concentration, motility, viability, morphology and sperm DNA damage

There was no statistically significant difference between the groups for the epididymal sperm concentration, total and progressive motility, viability (Fig. 1) and sperm DNA damage (DFI, Fig. 2). Furthermore, there was no significant difference between the groups regarding sperm morphology (percentage of sperm acrosome, head, neck, mid-piece and tail defects, cytoplasmic droplets and loose heads) (Table 4).

\section{Daily sperm production and testosterone}

There was no statistically significant difference between groups for DSP (Fig. 3) and blood plasma testosterone concentrations (Fig. 4).

\section{Discussion}

Knowledge about the effect of NMs on sperm quality is limited, especially following pulmonary exposure. Although various NMs have been reported to induce testicular toxicity and decrease semen quality, mainly oral and intravenous exposures have been investigated [9, 29]. This is somehow striking as inhalation is the major exposure route for NMs in humans, and the systemic inflammation which is induced after a pulmonary exposure may be an important indirect mechanism for the induction of testicular toxicity. In the current study, male mice were exposed via the lungs to four different carbonaceous NMs and the effects of these NMs on sperm quality parameters, measured as epidydimal sperm concentration, viability, motility, morphology, sperm DNA damage, DSP, and plasma testosterone concentrations, were investigated.

At a final cumulative dose of $700 \mu \mathrm{g} /$ mouse $(126 \mu \mathrm{g}$ for graphene oxide), the significant influxes of PMNs demonstrate pulmonary inflammation one week post exposure compared to the three control groups. Previous studies showed that instilled Printex 90 at a final cumulative dose of $268 \mu \mathrm{g} /$ mouse induced lung inflammation in terms of increased neutrophil influx and expression of

Table 2 Body weight (g), and absolute (mg) and relative weights of left testis and epididymis at the time of euthanasia

\begin{tabular}{|c|c|c|c|c|c|}
\hline & Body weight (g) & Testis weight (mg) & $\begin{array}{l}\text { Testis relative } \\
\text { weight }\end{array}$ & $\begin{array}{l}\text { Epididymal weight } \\
\text { (mg) }\end{array}$ & $\begin{array}{l}\text { Epididymal relative } \\
\text { weight }\end{array}$ \\
\hline Vehicle control & $39.39 \pm 3.19$ & $107.67 \pm 6.61$ & $2.75 \pm 0.23$ & $45.33 \pm 6.21$ & $1.15 \pm 0.14$ \\
\hline Graphene oxide & $40.26 \pm 3.82$ & $103.10 \pm 14.03$ & $2.58 \pm 0.37$ & $43.29 \pm 6.33$ & $1.08 \pm 0.14$ \\
\hline Flammruss 101 & $39.91 \pm 4.23$ & $107.91 \pm 15.43$ & $2.71 \pm 0.42$ & $39.49 \pm 9.32$ & $0.98 \pm 0.18$ \\
\hline Printex 90 & $37.96 \pm 2.15$ & $107.91 \pm 10.34$ & $2.85 \pm 0.25$ & $43.71 \pm 3.97$ & $1.15 \pm 0.11$ \\
\hline SRM1650b & $40.08 \pm 3.50$ & $103.14 \pm 17.46$ & $2.58 \pm 0.42$ & $41.09 \pm 12.41$ & $1.09 \pm 0.13$ \\
\hline Unhandled & $42.97 \pm 4.15$ & $107.78 \pm 11.14$ & $2.53 \pm 0.32$ & $45.03 \pm 2.48$ & $1.06 \pm 0.13$ \\
\hline High fat diet & $50.09 \pm 6.34^{a}$ & $111.77 \pm 7.45$ & $2.26 \pm 0.28$ & $46.16 \pm 3.09$ & $0.93 \pm 0.12$ \\
\hline
\end{tabular}

Mean \pm SD $(n=15)$

${ }^{a}<0.001$, compared with vehicle control 
Table 3 Pulmonary inflammation presented as total cell, macrophage and neutrophil counts in the BALF 6 to 8 days after the last instillation

\begin{tabular}{llll}
\hline & $\begin{array}{l}\text { Total cells } \\
\left(\times 10^{5}\right)\end{array}$ & $\begin{array}{l}\text { Macrophages } \\
\left(\times 10^{5}\right)\end{array}$ & $\begin{array}{l}\text { Neutrophils } \\
\left(\times 10^{5}\right)\end{array}$ \\
\hline $\begin{array}{l}\text { Vehicle } \\
\text { control }\end{array}$ & $10.95 \pm 0.73$ & $10.58 \pm 0.73$ & $0.04 \pm 0.02$ \\
$\begin{array}{l}\text { Graphene } \\
\text { oxide }\end{array}$ & $16.21 \pm 1.15^{\mathrm{a}}$ & $13.39 \pm 0.97$ & $2.07 \pm 0.39^{\mathrm{b}}$ \\
$\begin{array}{l}\text { Flammruss } \\
101\end{array}$ & $11.89 \pm 2.09$ & $8.85 \pm 0.79$ & $2.47 \pm 1.46^{\mathrm{b}}$ \\
Printex 90 & $27.90 \pm 2.96^{\mathrm{b}}$ & $19.09 \pm 2.06$ & $13.19 \pm 1.11^{\mathrm{b}}$ \\
SRM1650b & $14.78 \pm 1.24$ & $10.90 \pm 0.83$ & $3.15 \pm 0.56^{\mathrm{b}}$ \\
Unhandled & $12.56 \pm 1.25$ & $12.07 \pm 1.24$ & $0.11 \pm 0.02$ \\
High fat diet & $10.92 \pm 0.91$ & $10.18 \pm 0.92$ & $0.07 \pm 0.03$ \\
\hline
\end{tabular}

Mean \pm SD $(n=13-15)$

${ }^{\mathrm{a}}<0.05,{ }^{\mathrm{b}}<0.001$, compared with vehicle control

inflammatory and acute phase response both at mRNA and protein levels in the lung, including increased expression of chemokine ligand 5 ( $\mathrm{Cxcl} 5)$, serum amyloid A 3 (Saa3), immunoglobulin joining chain (Igj) and lymphocyte antigen 6 complex, locus F (Ly6f) [30]. This reflects that at high levels of $\mathrm{CB}$ exposure there is a proinflammatory response and an adaptive immune response. Based on our previous results, the observed neutrophil influx would suggest systemic inflammation at the applied cumulative dose levels. Despite the pulmonary inflammatory response we did not identify statistically significant differences in the investigated sperm parameters and testosterone concentrations between the particle exposed and vehicle control group.

Our results are in direct contrast to those described by Yoshida et al. (2008) who, at similar dose levels as in the present study, reported reduced DSP, seminiferous tubules damage and increased testosterone concentrations in ICR mice following ten instillations of Printex 90, and reduced DSP and seminiferous tubules damage following ten instillations of Flammruss 101 NPs [16]. The reason for this discrepancy is not clear. There are, however, major differences between the two studies in reference to mouse strain (NMRI versus ICR), number of instillations (seven versus ten), sampling time ( $24 \mathrm{~h}$ versus 6-8 days after the last instillation), and the vehicle used for the dispersion of particles (nanopure water versus saline with $0.05 \%$ tween 80 ).
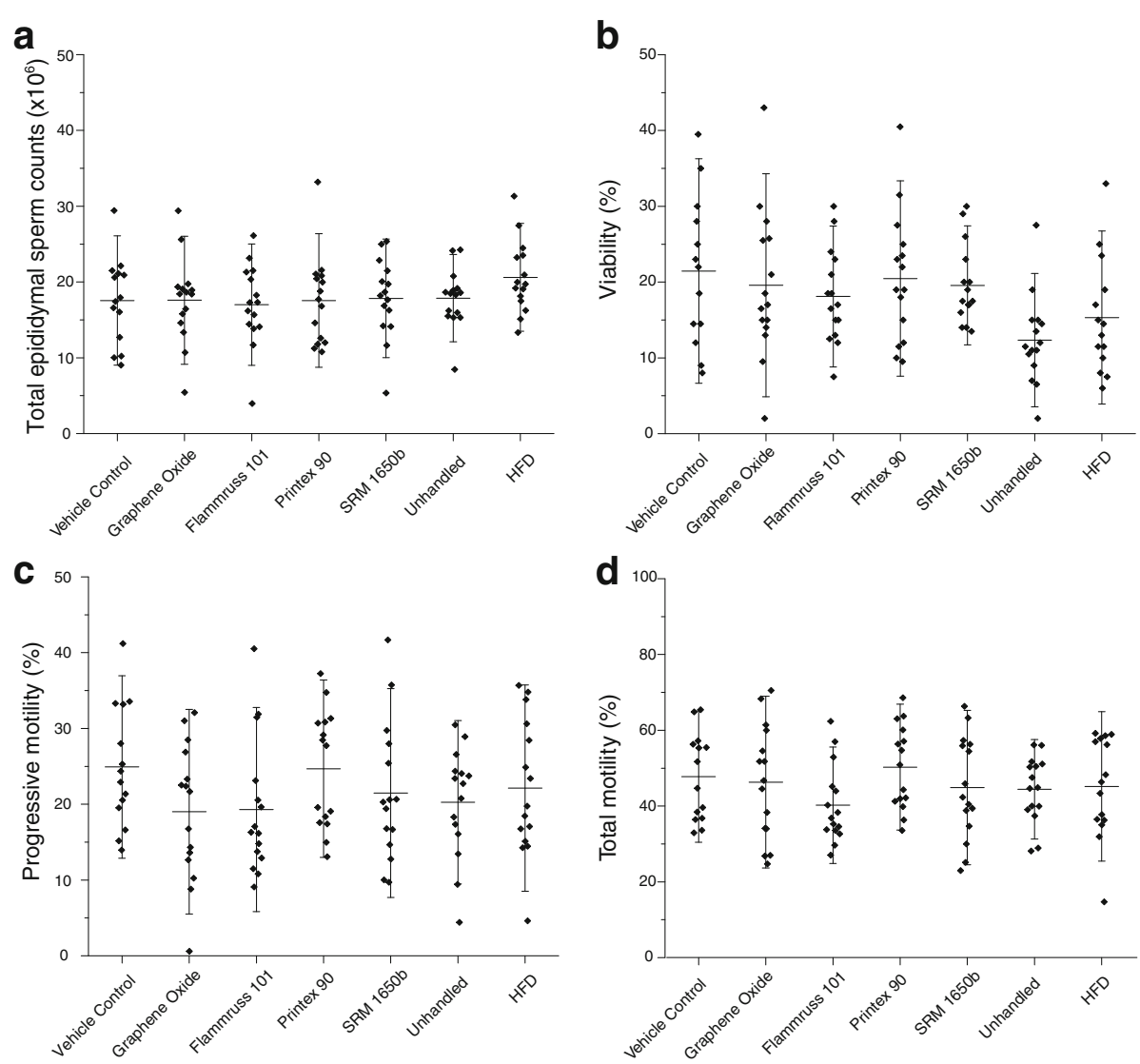

Fig. 1 Epididymal sperm parameters analysed from the left epididymal tail. a Total epididymal sperm counts $\left(\times 10^{6}\right)$ b Viable sperm (\%) c Progressive motility (\%) d Total motility (\%). Mean \pm SD $(n=14-15)$ 


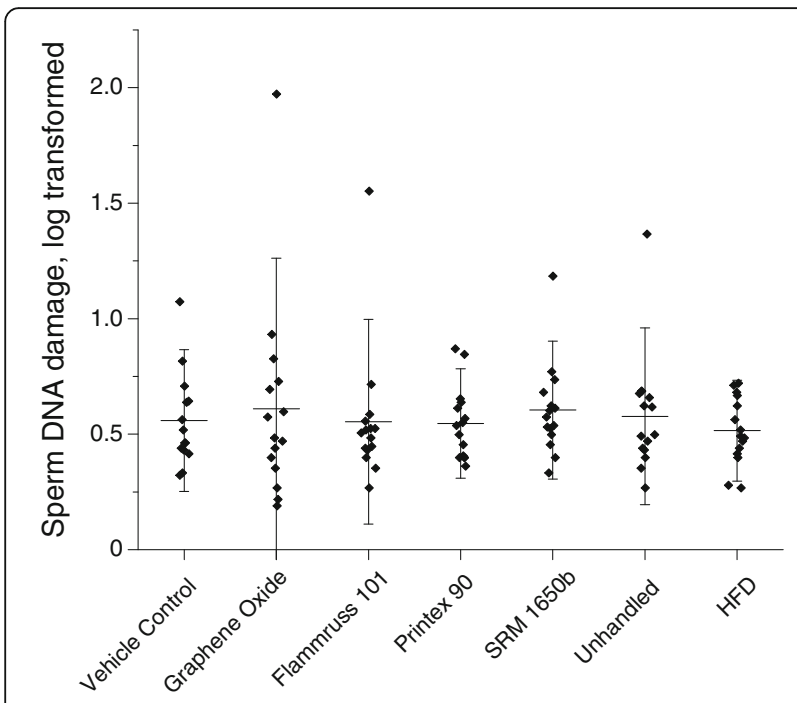

Fig. 2 DFI (Sperm DNA damage, log transformed). Mean \pm SD $(n=15)$

The use of different vehicles and dispersants warrants important consideration in studies of male reproductive toxicity of NMs, because the vehicle can potentially change the chemical and physical properties of the particles and thereby influence their bioavailability and thus their potential for toxic insult. Surfactant molecules, like tween, have both lipophilic and hydrophilic properties and are therefore able to partition between lipid and protein structures; they are also known to enhance permeability because of their effects on tight junctions and cellular membranes [31]. Studies in male mice dosed intravenously with graphene oxide $(1000 \mu \mathrm{g} / \mathrm{ml})$ with or without $1 \%$ tween 80 showed that graphene oxide alone appeared to have a higher retention in the lungs compared to the graphene oxide with tween 80 . In contrast, increased amounts of graphene oxide with tween 80 appeared to be retained in the liver. The authors concluded that tween 80 changes the zeta potential of particles and enables particles, like graphene oxide, to pass the capillary bed without massive deposition in the lungs [32].

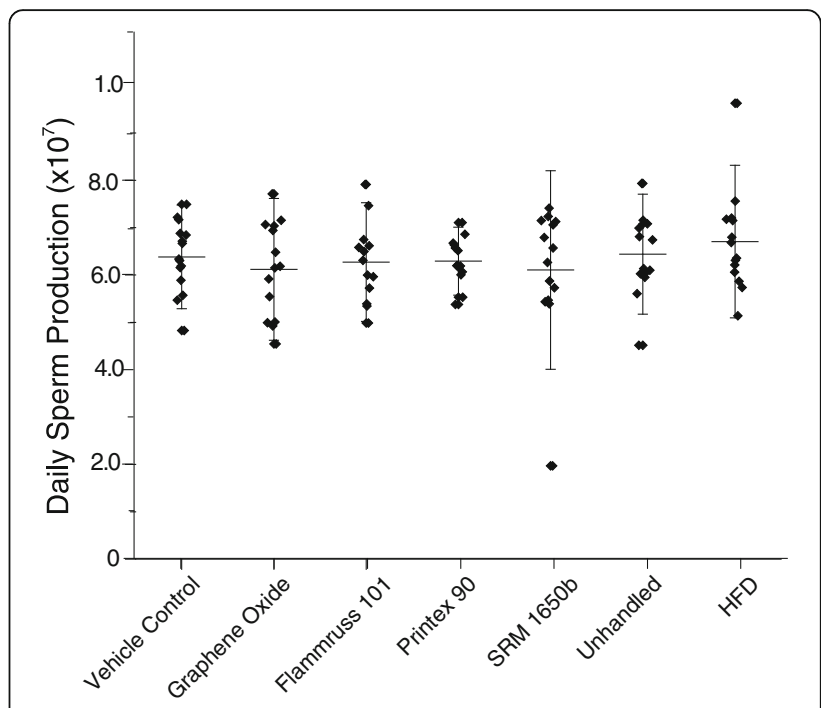

Fig. 3 Daily sperm production derived as spermatids in developmental stage 14 to 16 measured in the left testicle $\left(\times 10^{7}\right.$ spermatids).

Mean \pm SD $(n=13-15)$

Interestingly, no aggregates of graphene oxide or histopathological changes were found in the testis from mice in any of the graphene groups [32]. Nevertheless, Akhavan et al. [33] found accumulation of graphene oxide in the testis accompanied by significantly decreased epididymal sperm viability and motility, and increased sperm DNA damage and ROS generation in semen after an intravenous administration to BALB/c mice at a dose of $4 \mathrm{mg} / \mathrm{kg}$ of graphene oxide dispersed in PBS and DSPE-PEG- $\mathrm{NH}_{2}$ polymers. On the other hand, Liang et al. [34] found that intravenous administration of graphene oxide dispersed in PBS alone at $6.25,12.5$ and $25 \mathrm{mg} / \mathrm{kg}$ to ICR mice had no effect on epididymal sperm motility, morphology, concentration, male endogenous sex hormone and histology in the testis. Similarly, 10 instillations of Printex 90 dispered in 0.05\% tween 80 caused adverse effects on reproductive parameters [16], whereas 7 instillations of Printex 90 dispered in nanopure water alone did not (present study).

Table 4 Percentages of normal spermatozoa and of spermatozoa with morphological defects in the acrosome, head, neck, mid-piece or tail region, those having a cytoplasmic droplet and a loose head

\begin{tabular}{|c|c|c|c|c|c|c|c|c|}
\hline & Normal (\%) & Acrosome (\%) & Head (\%) & Neck (\%) & Mid-piece (\%) & Tail (\%) & $\begin{array}{l}\text { Cytoplasmic } \\
\text { droplets (\%) }\end{array}$ & Loose heads (\%) \\
\hline Vehicle control & $30.64 \pm 10.0$ & $16.7 \pm 10.3$ & $3.00 \pm 2.5$ & $5.39 \pm 2.4$ & $3.07 \pm 3.8$ & $33.54 \pm 8.2$ & $3.29 \pm 4.8$ & $4.32 \pm 3.5$ \\
\hline Graphene oxide & $24.50 \pm 13.5$ & $12.17 \pm 12.2$ & $2.77 \pm 2.7$ & $7.77 \pm 7.7$ & $4.83 \pm 7.1$ & $39.57 \pm 15.2$ & $2.37 \pm 2.3$ & $6.03 \pm 5.6$ \\
\hline Flammruss 101 & $29.86 \pm 8.1$ & $17.32 \pm 12.1$ & $4.32 \pm 2.5$ & $4.68 \pm 2.4$ & $0.82 \pm 1.0$ & $35.36 \pm 12.0$ & $2.28 \pm 3.1$ & $5.35 \pm 2.5$ \\
\hline Printex 90 & $28.23 \pm 10.7$ & $21.10 \pm 9.6$ & $2.56 \pm 1.2$ & $5.07 \pm 3.3$ & $2.00 \pm 1.9$ & $32.20 \pm 12.4$ & $2.17 \pm 3.0$ & $6.67 \pm 3.9$ \\
\hline SRM1650b & $26.26 \pm 9.5$ & $23.50 \pm 7.9$ & $4.76 \pm 4.1$ & $6.17 \pm 3.0$ & $2.30 \pm 1.7$ & $29.23 \pm 11.7$ & $1.43 \pm 1.7$ & $6.33 \pm 5.4$ \\
\hline Unhandled & $25.20 \pm 12.8$ & $18.87 \pm 9.7$ & $1.70 \pm 1.2$ & $4.37 \pm 2.0$ & $0.83 \pm 1.0$ & $36.83 \pm 10.5$ & $1.00 \pm 1.5$ & $10.80 \pm 16.9$ \\
\hline High fat diet & $26.63 \pm 10.1$ & $21.56 \pm 10.4$ & $3.63 \pm 1.6$ & $4.46 \pm 2.3$ & $1.47 \pm 1.5$ & $36.16 \pm 9.12$ & $1.33 \pm 1.4$ & $4.73 \pm 2.8$ \\
\hline
\end{tabular}




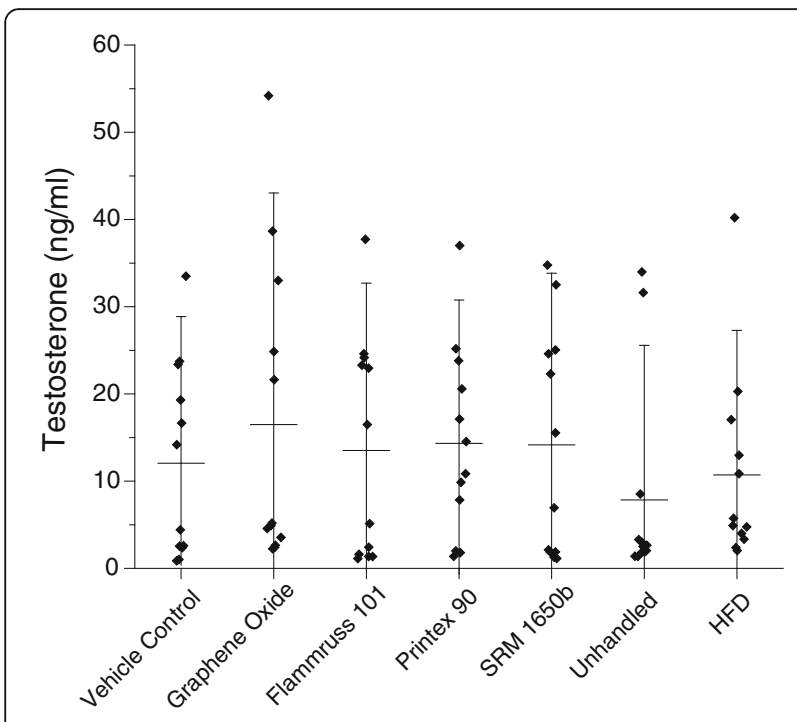

Fig. 4 Testosterone concentration $(\mathrm{ng} / \mathrm{ml})$ in plasma. Mean $\pm S D$ $(n=13-15)$

Translocation of titanium dioxide nanoparticles from lung to secondary tissues including liver and heart has been shown after intratracheal instillation of nano- $\mathrm{TiO}_{2}$ dispersed in $0.9 \% \mathrm{NaCl}$ MilliQ water with $10 \%$ acellular BAL fluid [35] or water [36]. Therefore, we might expect some degree of translocation into the systemic circulation of nanosized particles that were deposited in the lungs. However, in the present study, microscopical examination of the testis revealed no gross morphological alterations between the groups and there was no apparent indication of particle deposition in the testis (data not shown). A more comprehensive comparison on the potentially increased bioavailability to reproductive organs and the potential disruption of the blood-testis-barrier as well as testicular toxicity of surfactant coated and non coated NMs remains to be investigated.

Apart from surface coating, other physicochemical properties of the nanomaterials, such as size and core chemistry, may influence their effects on the male reproductive system [37]. Size-dependent effects on plasma testosterone are apparent in the paper by Yoshida et al. (2008), as plasma testosterone was increased for Printex 90 (primary particle size of $14 \mathrm{~nm}$ ) while it remained unchanged for Flammruss 101 (primary particles size of $95 \mathrm{~nm}$ ). We failed to reproduce this dependency on particle size, despite the evident differences in primary particle size of the carbonaceous NMs as well as the particle-induced inflammation.

In the present study, the nanomaterials were deposited in the lungs by instillation, i.e., the materials were delivered as a bolus. This typically results in a higher dose rate than during inhalation, and instillation may therefore not compare directly to real-life exposure. Instillation is very convenient for conduction of proof of principle studies and comparison of toxicity between studies and particles, as it ensures that similar doses can be delivered for all assessed particles. For Printex 90, we have, however, previously shown that inhalation and instillation may both induce strong and long lasting lung inflammation at estimated comparable deposited dose levels [20]. Furthermore, studies of the pulmonary global transcriptional responses following inhalation and pulmonary exposure to two different nanomaterials suggest that the global transcriptional responses to inhaled and instilled or aspirated nanomaterials are very similar [38, 39].

Spermatogenesis is a steady state process and the ability to regenerate germ cell populations and recover functional spermatogonia after toxic insult are good. In fact, full recovery after an intratracheal instillation of $2 \mathrm{mg} / \mathrm{kg}$ of micelle coated silica NPs $(57.66 \mathrm{~nm})$ dispersed in saline has been observed [17]. Approximately thirty days after the last exposure, TEM images revealed that the silica particles could no longer be observed in the testis of C57 mice, and the reduced sperm motility and increased sperm abnormalities and apoptosis had been reversed [17]. Potentially, induced effects may have been reversed in our study one week after the last instillation, when the tissue samples were collected. However, at the time of necropsy, the observed pulmonary inflammation indicated pulmonary presence of the particles. Pulmonary translocation of NMs is an ongoing process and would still be occuring for days following the last instillation. Time dependent translocation has been shown in rats. Hence instilled radioisotopes of nanosized Cerium-141 were measured at significantly higher levels 28 days post-instillation in the blood, liver and spleen compared to day seven post-instillation [40]. With regards to timedependent translocation to the testis, multiwalled carbon nanotubes dispersed in PBS and $0.1 \%$ tween 80 administered intravenously at a dose of $5 \mathrm{mg} / \mathrm{kg}$ to BALB/c mice showed an increased trend of translocation to the testis; 41, 61 and $151 \mathrm{ng}$ were found in the testis $10 \mathrm{~min}$, $60 \mathrm{~min}$ and $24 \mathrm{~h}$ post-exposure, respectively. The authors concluded that after repeated administration the multiwalled carbon nanotubes would continue to accumulate in the testis, and certain effects could be observed up to 15 days post-instillation. Furthermore, during week eight (day 56) when our experiment was terminated and organs were collected, the spermatids in the epididymides would correspond to those in the testis during the first and second instillations, as spermatogenesis in mice takes 35 days plus approximately 14 days for epididymal maturation. We therefore postulate that if there would have been significant testicular toxicity, either by direct effect of the particles or indirectly by the 
inflammation, it would have been detected one week after the last instillation in the present study.

The HFD was chosen as a positive control because it has been previously shown to have a negative impact on semen quality in mice, e.g. by decreasing sperm motility, increasing oxidative stress (measured by intracellular ROS) and increasing sperm DNA damage [41]. However, the selection of a HFD as a positive control is a critical limitation to the study. Only one third of the mice in the HFD control group gained sufficient weight to be regarded as obese and therefore the effects, for examples on motility, may have not been detected (see Additional file 2). Suceptibility to HFD based adipose tissue inflammation and lipid peroxidative damage in muscle and liver have been shown to be strain specific [41]. In addition, it has been previously reported that semen quality and suceptibility to toxic insult may vary greatly between mouse strains [42, 43]. For example, the inflammatory marker TNF- $\alpha$ was significantly upregulated in the epididymal adipose tissue of $\mathrm{BALB} / \mathrm{c}$ and $\mathrm{FVB} / \mathrm{N}$ mice fed a HFD, while TNF- $\alpha$ remained unchanged in $\mathrm{BL} / 6,129 / \mathrm{X} 1$ and DBA/2 mice fed with the same diet [41]. The use of different mouse strains and experimental models in studies of male reprotoductive toxicity may provide some explanation to the contradictive results often encountered in this field.

To our knowledge, the present study is the first to investigate male reproductive toxicity of carbonaceous NMs administered via the lung, without the use of surfactants like tween 80 . The strength of the study is that all instilled mice, including the vehicle controls, underwent the same exposure procedure and received the same vehicle. We are therefore confident that there is no added effect from the procedure or the choice of vehicle, as confirmed by the similar low levels of neutrophils in the vehicle control compared to the unhandled and HFD groups reciving no instillation. Several of the assays presented here, such as the DSP [44], testosterone ELISA (unpublished data), and DNA damage [27, 28] assays were validated prior to this experiment. $A n$ a priori power analysis indicated that the chosen group size in this study $(n=15)$ provided a $95 \%$ chance of detecting approximately a one-fold difference at the 5\% significance level.

\section{Conclusion}

In the present experiment, our results suggest that sperm quality parameters (epidydimal sperm concentration, sperm viability, sperm motility, sperm morphology, sperm DNA damage, DSP, and plasma testosterone concentration) were not altered in the exposed groups compared to the controls, neither by direct action of the NMs nor indirectly from the inflammatory response, after eight weeks of exposure to graphene oxide (18 mg/mouse/i.t.), Flammruss
101, Printex 90 and the SRM1650b (each $0.1 \mathrm{mg} / \mathrm{mouse} /$ i.t.) dispersed in nanopure water, in the NMRI mouse model. Standardization of experimental procedures, e.g. use of vehicle, in studies of male reproductive toxicity of NMs are needed in order to have a collective conclusion on the effects of NMs on male reproductive function. This may be imperative when determining legislative measures on workplace exposure levels for men in the reproductive age.

\section{Additional files}

Additional file 1: Deposited surface area PMN. Neutrophil influx plotted against deposited surface area. (PDF $5 \mathrm{~kb}$ )

Additional file 2: Weight vs motility. Plot showing inverse correlation between progressive motility and body weight of mice. (PDF 7 kb)

\section{Abbreviations \\ BALF: Bronchoalveolar lavage fluid; CASA: Computer assisted sperm analysis; CB: Carbon black; DSP: Daily sperm production; HFD: High fat diet; \\ i.t.: Intratracheal instillation; NMs: Nanomaterials; NPs: Nanoparticles; PAH: Polycyclic aromatic hydrocarbons; PBS: Phosphate-buffered saline; ROS: Reactive oxygen species; SD: Standard deviation; SRM: Standard reference material}

\section{Acknowledgements}

The technical assistance from Michael Guldbrandsen, Eva Terrida, Natascha Synnøve Olsen and Inge Christensen was greatly appreciated.

\section{Funding}

The Danish Centre for Nanosafety II at the National Research Centre for the Working Environment and the Department of Large Animal Sciences/ Department of Veterinary Clinical Sciences, University of Copenhagen supported this PhD-study.

\section{Availability of data and materials}

Datasets used and/or analysed during the current study are available from the corresponding author on reasonable request.

\section{Authors' contributions}

AS performed all exposures and most of the animal handling, participated in the semen analysis, performed the daily sperm production, analysed and interpreted the datasets and drafted the manuscript. AL performed the testosterone measurements. PC performed the analyses of sperm DNA integrity. SGP was overall responsible for the semen analysis. KSH conceived the idea and drafted the study protocol, with UV suggesting the particles to include. SGP, KSH and UV all contributed to the final study protocol and gave major guidance and input during the study and writing of the manuscript. All authors read and approved the final manuscript.

\section{Ethics approval}

All experimental procedures performed on the animals respected the handing guidelines established by the Danish government and all the experimental protocols were approved by the Animal Ethics Council (no. 201515-0201-00465 and 2015-15-0201-00569).

Consent for publication Not applicable.

\section{Competing interests}

All authors declare that they have no competing interests.

\section{Publisher's Note}

Springer Nature remains neutral with regard to jurisdictional claims in published maps and institutional affiliations. 


\section{Author details}

${ }^{1}$ The National Research Center for the Working Environment, Lersø Parkallé, DK-2100 Copenhagen $\varnothing$, Denmark. ${ }^{2}$ Section for Veterinary Reproduction and Obstetrics, Department of Veterinary Clinical Sciences, University of Copenhagen, Dyrlægvej 68, DK-1870 Frederiksberg C, Denmark. ${ }^{3}$ SPZ Lab A S, Fruebjergvej 3, DK-2100 København $\varnothing$, Denmark. ${ }^{4}$ Department of Microand Nanotechnology, Technical University of Denmark, DK-2800 Kongens Lyngby, Denmark. ${ }^{5}$ Department of Public Health, University of Copenhagen, Øster Farimagsgade 5, DK-1014 Copenhagen K, Denmark.

\section{Received: 16 October 2017 Accepted: 8 January 2018} Published online: 31 January 2018

\section{References}

1. Bonde JP. Male reproductive organs are at risk from environmental hazards. Asian J Androl. 2009;12(2):152-6.

2. Sengupta $P$, Borges $E$, Dutta S, Krajewska-Kulak E. Decline in sperm count in European men during the past 50 years. Hum Exp Toxicol. 2017; https://doi. org/10.1177/0960327117703690.

3. Jørgensen $\mathrm{N}$, Nordstrom Joensen $\mathrm{U}$, Kold Jensen T, Blomberg Jensen $\mathrm{M}_{\text {, }}$ Almstrup K, Ahlmann Olesen I, Juul A, Andersson AM, Carlsen E, Holm Petersen J, Toppari J, Skakkebæk NE. Human semen quality in the new millennium: a prospective cross-sectional population-based study of 4867 men. BMJ Open. 2012:62:1197-8.

4. Sengupta P, Dutta S, Krajewska-Kulak E. The disappearing sperms: analysis of reports published between 1980 and 2015. Am J Mens Health. 2016; https://doi.org/10.1177/1557988316643383.

5. World Health Organization. Air quality guidelines for particulate matter, ozone, nitrogen dioxide and sulfur dioxide: global update 2005: summary of risk assessment. Geneva World Heal Organ. 2006;1-22. http://apps.who. int/iris/bitstream/10665/69477/1/WHO_SDE_PHE_OEH_06.02_eng.pdf.

6. Selevan SG, Borkovec L, Slott VL, Zudová Z, Rubeš J, Evenson DP, Perreault SD. Semen quality and reproductive health of young Czech men exposed to seasonal air pollution. Environ Health Perspect. 2000;108(9):887-94.

7. Lafuente R, Garcia-Blaquez N, Jacquemin B, Checa MA. Outdoor air pollution and sperm quality. Fertil Steril. 2016;106:880-96.

8. Oberdörster G, Sharp Z, Atudorei V, Elder A, Gelein R, Lunts A, Kreyling W. Extrapulmonary translocation of ultrafine carbon particles following whole-body inhalation exposure of rats. J Toxicol Environ Health. 2002; 65:1531-43

9. Lan Z, Yang WX. Nanoparticles and spermatogenesis: how do nanoparticles affect spermatogenesis and penetrate the blood-testis barrier. Nanomedicine. 2012;7:579-96.

10. Hedger MP. Testicular leukocytes: what are they doing? Rev Reprod. 1997;2:38-47.

11. Manke A, Wang L, Rojanasakul Y. Mechanisms of nanoparticle-induced oxidative stress and toxicity. Biomed Res Int. 2013; https://doi.org/10.1155/ 2013/942916

12. Sharma $R$, Agarwal A. Role of reactive oxygen species in male infertility. Urology. 1996;48(6):835-50

13. Johansson HKL, Hansen JS, Elfving B, Lund SP, Kyjovska ZO, Loft S, Barford KK, Jackson P, Vogel U, Hougaard KS. Airway exposure to multi-walled carbon nanotubes disrupts the female reproductive cycle without affecting pregnancy outcomes in mice. Part Fibre Toxicol. 2017; https://doi.org/10. 1186/s12989-017-0197-1.

14. Ramdhan DH, Ito $Y$, Yanagiba $Y$, Yamagishi N, Hayashi $Y$, Li C, Taneda S, Suzuki A, Watanabe G, Taya K, Kamijima M, Nakajima T. Nanoparticle-rich diesel exhaust may disrupt testosterone biosynthesis and metabolism via growth hormone. Toxicol Lett. 2009;191:103-8.

15. Yoshida S, Sagai M, Oshio S, Umeda T, Ihara T, Sugamata M, Sugawara I, Takeda K. Exposure to diesel exhaust affects the male reproductive system of mice. Int J Androl. 1999;22:307-15.

16. Yoshida S, Hiyoshi K, Ichinose T, Takano H, Oshio S, Sugawara I, Takeda K, Shibamoto T. Effects of nanoparticles on the male reproductive system of mice. Int J Androl. 2008:32:337-42.

17. Ren L, Zhang J, Zou Y, Zhang L, Wei J, Shi Z, Li Y, Guo C, Sun Z, Zhou X. Silica nanoparticles induce reversible damage of spermatogenic cells via RIPK1 signal pathways in C57 mice. Int J Nanomedicine. 2016;11:2251-64.

18. Jackson $\mathrm{P}$, Lund SP, Kristiansen G, Andersen $\mathrm{O}$, Vogel U, Wallin $\mathrm{H}$, Hougaard KS. An experimental protocol for maternal pulmonary exposure in developmental toxicology. Basic Clin Pharmacol Toxicol. 2011;108:202-7.

19. Zhang R, Dai Y, Zhang X, Niu Y, Meng T, Li Y, Duan H, Bin P, Ye M, Jia X, Shen $M, Y u$ S, Yang $X$, Gao W, Zheng Y. Reduced pulmonary function and increased pro-inflammatory cytokines in nanoscale carbon black-exposed workers. Part Fibre Toxicol. 2014;11(1):73.

20. Jackson P, Hougaard KS, Boisen AMZ, Jacobsen NR, Jensen KA, Møller P, Brunborg G, Gutzkow KB, Andersen O, Loft S, Vogel U, Wallin H. Pulmonary exposure to carbon black by inhalation or instillation in pregnant mice: effects on liver DNA strand breaks in dams and offspring. Nanotoxicology. 2012;6(5):486-500.

21. The Danish Working Environment Authority. At-vejledning. Stoffer og Materiale. Danish Work Environ Auth. 2017AD;C.0.1:1-84.

22. Bengtson S, Knudsen KB, Kyjovska ZO, Berthing T, Skaug V, Levin M, Koponen IK, Shivayogimath A, Booth TJ, Alonso B, Pesquera A, Zurutuza A, Thomsen BL, Troelsen JT, Jacobsen NR, Vogel U. Differences in inflammation and acute phase response but similar genotoxicity in mice following pulmonary exposure to graphene oxide and reduced graphene oxide. PLoS ONE. 2017; https://doi.org/10.1371/ journal.pone.0178355.

23. Bengtson S, Kling K, Madsen AM, Noergaard AW, Jacobsen NR, Clausen PA, Alonso B, Pesquera A, Zurutuza A, Ramos R, Okuno H, Dijon J, Wallin $\mathrm{H}$, Vogel $U$. No cytotoxicity or genotoxicity of graphene and graphene oxide in murine lung epithelial FE1 cells in vitro. Environ Mol Mutagen. 2016:57:469-82.

24. Saber AT, Jensen KA, Jacobsen NR, Birkedal R, Mikkelsen L, Møller P, Loft S, Wallin H, Vogel U. Inflammatory and genotoxic effects of nanoparticles designed for inclusion in paints and lacquers. Nanotoxicology. 2012;6:453-71.

25. Kyjovska ZO, Jacobsen NR, Saber AT, Bengtson S, Jackson P, Wallin H, Vogel U. DNA strand breaks, acute phase response and inflammation following pulmonary exposure by instillation to the diesel exhaust particle NIST1650b in mice. Mutagenesis. 2015;30:499-507.

26. Kyjovska ZO, Jacobsen NR, Saber AT, Bengtson S, Jackson P, Wallin H, Vogel UDNA. Damage following pulmonary exposure by instillation to low doses of carbon black (printex 90) nanoparticles in mice. Environ Mol Mutagen. 2010;51:229-35

27. Evenson D, Jost L. Sperm chromatin structure assay for fertility assessment. Meth in Cell Sci. 2000;22:169-89.

28. Boe-Hansen GB, Ersbøll AK, Christiensen P. Variability and laboratory factors affecting the sperm chromatin structure assay in human semen. J Androl. 2005;26:360-8.

29. Ema M, Hougaard KS, Kishimoto A, Honda K. Reproductive and developmental toxicity of carbon-based nanomaterials: a literature review. Nanotoxicology. 2016;10:1-22.

30. Jackson P, Hougaard KS, Vogel U, Wu D, Casavant L, Williams A, Wade M, Yuak $\mathrm{CL}$, Wallin H. Halappanavar. Exposure of pregnant mice to carbon black by intratracheal instillation: Toxicogenomic effects in dams and offspring. Mutat Res Genet Toxicol Environ Mutagen. 2012;745(1-2):73-83.

31. Kaur G, Mehta SK. Developments of Polysorbate (tween) based microemulsions: preclinical drug delivery, toxicity and antimicrobial applications. Int J Pharm. 2017;529:134-60.

32. Qu G, Wang X, Liu Q, Liu R, Yin N, Ma J, Chen L, He J, Liu S, Jiang G. The ex vivo and in vivo biological performances of graphene oxide and the impact of surfactant on graphene oxide's biocompatibility. J Environ Sci. 2013;25:873-81.

33. Akhavan O, Ghaderi E, Hashemi E, Akbari E. Dose-dependent effects of nanoscale graphene oxide on reproduction capability of mammals. Carbon. 2015:95:309-17.

34. Liang S, Xu S, Zhang D, He J, Chu M. Reproductive toxicity of nanoscale graphene oxide in male mice. Nanotoxicology. 2015;9:1-14.

35. Husain M, Wu D, Saber AT, Decan N, Jacobsen NR, Williams A, Yuak CL, Wallin H, Vogel U, Halappanavar S. Intratracheally instilled titanium dioxide nanoparticles translocate to heart and liver and activate complement cascade in the heart of C57BL/6 mice. Nanotoxicology. 2015;9(8):1013-22.

36. Kreyling WG, Holzwarth U, Schleh C, Kozempel J, Wenk A, Haberl N, Hirn S, Schaffler M, Lipka J, Semmler-Behnke M, Gibson N. Quantitative biokinetics of titanium dioxide nanoparticles after oral application in rats: part 2. Nanotoxicology. 2017;11(4):443-53.

37. Campagnolo L, Massimiani M, Magrini A, Camaioni A, Pietroiusti A. Physicochemical properties mediating reproductive and developmental toxicity of engineered nanomaterials. Curr Med Chem. 2012;19:4488-94. 
38. Kinaret P, Ilves M, Fortino V, Rydman E, Karisola P, Lahde A, Koivisto J, Jokiniemi J, Wolff H, Savolainen K, Greco D, Alenius H. Inhalation and oropharyngeal aspiration exposure to rod-like carbon nanotubes Induse similar airway inflammation and biological responses in mouse lungs. ACS Nano. 2017;11:291-303.

39. Husain M, Saber A, Guo C, Jacobsen N, Jensen K, Yauk C, Willims A, Vogel U, Wallin $\mathrm{H}$. Halappanavar. Pulmonary instillation of low doses of titation dioxide nanoparticles in mice leads to particle retention and gene expression changes in the absence of inflammation. Tox Appl Pharma. 2013; 269(3):250-02.

40. He X, He X, Zhang H, Ma Y, Bai W, Zhang Z, Lu K, Ding Y, Zhao Y, Chai Z. Lung deposition and extrapulmonary translocation of nano-ceria after intratracheal instillation. Nanotechnology. 2010; https://doi.org/10.1088/ 0957-4484/21/28/285103.

41. Montgomery MK, Hallahan NL, Brown SH, Liu M, Mitchell TW, Cooney GJ, Turner N. Mouse strain-dependent variation in obesity and glucose homeostasis in response to high-fat feeding. Diabetologia. 2013:56:1129-39.

42. Krzanowska H. Sperm head abnormalities in relation to the age and strain of mice. J Reprod Fert. 1981;62:385-92.

43. Thurston LM, Watson PF, Holt WV. Semen cryopreservation: a genetic explanation for species and individual variation? CryoLetters. 2002;23: 255-62.

44. Kyjovska ZO, Boisen AMZ, Jackson P, Wallin H, Vogel U, Hougaard KS. Daily sperm production: application in studies of prenatal exposure to nanoparticles in mice. Reprod Toxicol. 2013;36:88-97.

\section{Submit your next manuscript to BioMed Central and we will help you at every step:}

- We accept pre-submission inquiries

- Our selector tool helps you to find the most relevant journal

- We provide round the clock customer support

- Convenient online submission

- Thorough peer review

- Inclusion in PubMed and all major indexing services

- Maximum visibility for your research

Submit your manuscript at www.biomedcentral.com/submit 